\title{
STEM Lesson - tow a wheeled object
}

Adrián Castrillo ${ }^{1}$

${ }^{1}$ Affiliation not available

May 18, 2021

\section{S.T.E.M Challenge - The Tow Challenge}

Grade/Level: 7 th

Time Allotment: The total duration of The Tow Challenge is 60 minutes. In this time, the person in charge of the class will allocate time as follows:

5 minutes: explanation of the challenge and QA off from such explanation.

5 minutes: present the materials that can be used in the challenge.

45 minutes: students completing the challenge.

5 minutes: open discussion among the students.

Type of Technology: Construction, forces, Math, and Physics

\section{Challenge:}

Each group within the class is challenged to Tow a 4 -wheeled dolly with the rest of the class standing on it.

\section{Essential Question or Problem to be Solved:}

Can you build a towing mechanism using only the provided materials?

\section{Student Learning Outcomes:}

- Understand the science and physics behind pull forces.

- Understand the different strengths of materials.

- Calculate the force needed to pull a given weight. 
- Use and understand the Engineering Design Process when creating a structure.

- Openly discuss their experimentation findings with their classmates to reiterate and come up with a better solution.

\section{Materials:}

\section{Teacher Materials:}

- Masking Tape (2)

- Measuring Tape (1)

- Sharpie/Marker (1)

- 4 wheeled dolly (1 - big enough to hold at least 4 students/2 teachers on top of it)

\section{Team Materials:}

- Sheets of newspaper (50 pages of US Broadsheet newspapers)

- Sharpie/Marker (1)

- Straws (10)

- Scissors (1)

- Rope (1 foot)

- Masking Tape (3 Feet)

- Aluminum Foil (1)

- Letter-sized sheets (3)

\section{Lesson Plan Background Information}

This lesson is intended to provide some introductory knowledge to students on the forces of Physics. The students are tasked to build a towing mechanism out of the provided materials and within the timeframe allotted.

This lesson meets the requirements for the STEM.org STEM Lesson Checklist with a self assessment score of 16 . This is the link to this checklist.

\section{Implementation}

\section{Teacher Prep}

- Meet with other teachers that will introduce the cross-curricular lessons.

- Gather all materials listed for the prerequisite knowledge lessons and the challenge.

- Review the prerequisite knowledge lessons and teach them before the challenge.

- Divide the class into teams of 3-4 students.

- Pick the students or teachers that will be on top of the dolly.

- Use masking tape, the measuring take, and the sharpie to create a ruler on the floor to measure the distance. 


\section{Engineering Design Process}

- ASK - Define the problem for the Tow Challenge.

- IMAGINE - Brainstorm possible solutions to the problem: what mechanism can we build to tow the dolly over the longest possible distance?

- PLAN - Sketch the ideas for the towing mechanism on the paper sheets.

- CREATE - Build the towing mechanism.

- IMPROVE - Test your design using the 4-wheeled dolly without any weight on it. How can the design be improved? How will it hold with weight on it?

- COMMUNICATE - Write down step by step instructions that explain how to build the towing mechanism.

\section{Procedure/Method}

It is up to each student to build the prototype as they see convenient. There is no guidance or mandate on what a successful towing mechanism looks like.

Ideally, the dolly will be placed in one of a court or street with no weight on it.

The students will build the towing mechanism using only the provided materials.

If required, the "Captain" of the dolly (to be chosen by the teacher) will be the person responsible to hold the towing mechanism.

The towing mechanism can be attached to the dolly using only the provided materials.

The team towing the dolly can command the people in the dolly where to place themselves.

\section{Cross Curricular/Interdisciplinary}

\begin{tabular}{lll}
\hline Mathematics & Science & Language \\
\hline Applied math & Physics & Communication \\
Calculations & Forces & \\
\hline
\end{tabular}

\section{Assessment}

The teacher will measure the distance that the dolly covered with the weight on top of it.

The teacher will award points based on how much distance it was able to cover.

The teacher will award points based on the way the materials were put together and how well they hold the forces of pulling the dolly. 